(1972).

(3) E. P. Parry, J. Catal., 2, 371 (1963).

(4) M. R. Basila, T. R. Kantner, and K. H. Rhee, J. Phys. Chem., 68, 3197 (1964).

(5) J. Sonnemans, F. Goudriaan, and P. Mars, Proc. Int. Congr. Catal., 5th, part II, 1085 (1972).

(6) F. E. Kiviat and L. Petrakis, J. Phys. Chem., 77, 10, 1232 (1973),

(7) T. Fransen, O. van der Meer, and P. Mars, J. Catal., 42, 79 (1976)

(8) J. Sonnemans and P. Mars, J. Catal, 31, 209 (1973).

(9) P. Bourret, J. Lecuire, and C. Weiss, Chim. Anal., 52, 48 (1970)

(10) P. Sondag, D. Q. Kim, and F. Marion, C.R. Acad. Sci. Paris, 259, 8, 4704 (1964).

(11) F. E. Massoth, J. Catal., 30, 204 (1973)

(12) J. Masson and J. Nechtschein, Bull. Soc. Chim. Fr., 10, 3933 (1968)

(13) D. Cook, Can. J. Chem., 39, 2009 (1961).

(14) J. Sonnemans, G. H. van den Berg, and P. Mars, J. Catal., 31, 220 (1973).

(15) T. Fransen, P. C. van Berge, and P. Mars, manuscript in preparation.
(16) K. S. Seshadrl and L. Petrakis, J. Catal., 30, 195 (1973).

(17) H. Knözinger and H. Stolz, Fortschr. Kolloid. Polym., 55, 16 (1971).

(18) F. Pratesi and R. Freymann, C.R. Acad. Sci. Paris, Ser. B, 266, 327 (1968).

(19) F. Goudriaan, Thesis, Twente University of Technology, The Netherlands, 1974 (in English).

(20) F. A. Andersen, B. Bak S. Brodersen, and J.Rastrup-Andersen, J. Chem. Phys., 23, 6, 1047 (1955).

(21) L. Corrsin, B. J. Fax, and R. C. Lord, J. Chem. Phys., 21, 7, 1170 (1953).

(22) W. K. Hàll and F. E. Massoth, J. Catal., 34, 41 (1974).

(23) T. Fransen, J. Hofman, and P. Mars, unpublished results.

(24) J. Sonnemans, J. Janus, and P. Mars, J. Phys. Chem., following paper in this issue.

(25) A. S. Russell and J. J. Stokes Jr., Ind. Eng. Chem., 38, 1071 (1946).

(26) M. Dufaux. M. Che, and C. Naccache, J. Chim. Phys., 67, 527 (1970)

(27) A. Ismayel-Milanovic, J. M. Basset, H. Praliaud, M. Dufaux, and L. de Mourgues, J.Catal, 31, 408 (1973)

\title{
Surface Structure and Catalytic Activity of a Reduced Molybdenum Oxide-Alumina Catalyst. 2. The Mechanism of Pyridine Hydrogenation and Piperidine Dehydrogenation
}

\author{
J. Sonnemans, † J. M. Janus, and P. Mars* \\ Twente University of Technology, Department of Chemistry, Enschede, The Netherlands (Recelved January 16, 1976) \\ Publication costs assisted by the Twente University of Technology
}

The dehydrogenation of piperidine has been studied and found to have an order of -1.5 with respect to the hydrogen partial pressure. By combining these results with those obtained for pyridine hydrogenation on the same catalyst a complete rate equation for piperidine dehydrogenation together with the stoichiometric number of the rate-determining step of these reactions could be derived. This number appeared to be one. A mechanism for pyridine hydrogenation is presented on the basis of these results and those from adsorption studies using the infrared spectroscopic technique. The rate-determining step is found to be the formation of adsorbed trihydropyridine.

\section{Introduction}

Hydrogenation of aromatic nitrogen containing compounds is the first step for their denitrogenation on metal oxide or sulfide catalysts, such as $\mathrm{CoO}-\mathrm{MoO}_{3}-\mathrm{Al}_{2} \mathrm{O}_{3} \cdot{ }^{1-4}$ The kinetics of this hydrogenation has been studied with the aid of model compounds such as quinoline ${ }^{2}$ and pyridine. ${ }^{3,5}$ Only little information is available regarding the mechanism of this hydrogenation, the active sites, and the rate-determining step.

The kinetics of the hydrogenation of pyridine has been studied by varying the temperature, the reaction time, the pyridine partial pressure, and the hydrogen pressure. The conversion as a function of the reaction time shows a firstorder process. ${ }^{3,6}$ However, the rate constant is found to be inversely proportional to the initial pyridine partial pressure. ${ }^{3,5}$ An explanation for these results, also observed for other nitrogen containing compounds, ${ }^{7}$ can be given by considering the rate equation ${ }^{5}$

†Present address: AKZO Chemie Nederland B.V., Amsterdam-N, The Netherlands.

$$
-\frac{\mathrm{d} P_{\mathrm{py}}}{\mathrm{d} t}=k_{1} \theta_{\mathrm{py}} P_{\mathrm{H}_{2}}{ }^{a}=\frac{k_{1} b_{\mathrm{py}} P_{\mathrm{py}} P_{\mathrm{H}_{2}}{ }^{a}}{1+b_{\mathrm{py}} P_{\mathrm{py}}+\Sigma b_{\mathrm{prod}} P_{\mathrm{prod}}}
$$

where $\theta_{\mathrm{i}}$ is the degree of occupation, $b_{\mathrm{i}}$ the adsorption constant of compound i, $P$, the partial pressure, and $k_{1}$, the rate constant.

A Langmuir type of adsorption of the nitrogen bases has been assumed. The adsorption of hydrogen and nitrogen bases occur on different sites ${ }^{5}$ and experiments with the volumetric technique confirmed that the presence of nitrogen bases does not influence the rate of hydrogen chemisorption. ${ }^{8}$

Because the adsorption constants of the nitrogen bases appear to be almost equal and $b_{\mathrm{N}} P_{\mathrm{N}_{0}} \gg 1\left(P_{\mathrm{N}_{0}}=\right.$ total pressure of the nitrogen base), this equation can be simplified as

$$
-\frac{\mathrm{d} P_{\mathrm{py}}}{\mathrm{d} t}=k_{1} \frac{P_{\mathrm{py}}}{P_{\mathrm{N}_{0}}} P_{\mathrm{H}_{2}}{ }^{a}
$$

The influence of hydrogen pressure has been studied by varying this pressure from 15 to $75 \mathrm{~atm} .5$ The results obtained at 300 and $375^{\circ} \mathrm{C}$ show the order with respect to hydrogen to be 1.5-1.6 (Figure 1). A discussion on details of the mechanism 


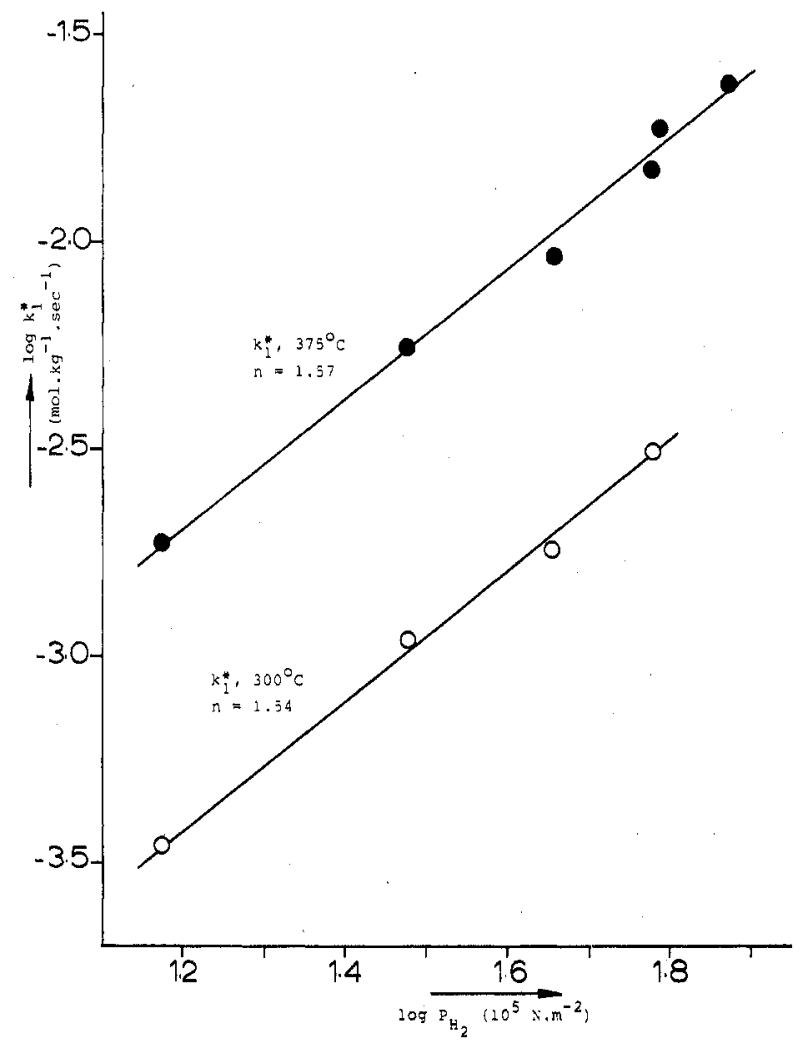

Figure 1. Effect of the hydrogen pressure on the pseudo rate constant of the pyridine hydrogenation at 300 and $375^{\circ} \mathrm{C}$ (values from Table II in ref 5$):(0)=k_{1}{ }^{*}$ at $300^{\circ} \mathrm{C} ;(0) k_{1}{ }^{*}$ at $375^{\circ} \mathrm{C}$.

could not be given due to lack of data on the piperidine dehydrogenation.

The conversion of piperidine has been studied at 300 and $325^{\circ} \mathrm{C}$. It was shown 7 that the (hydro)cracking of piperidine can be described by the following equation:

$$
-\frac{\mathrm{d} P_{\text {pip }}}{\mathrm{d} t}=k_{2} \frac{P_{\text {pip }} P_{\mathrm{H}_{2}}}{P_{\text {pip }_{0}}}
$$

At these temperatures the conversion into pyridine is less than $1 \%$ of the total amount of products formed (Figure 1 in ref 7 ), so that no conclusions about the dehydrogenation reaction could be drawn.

In this paper, experiments on the piperidine conversion at higher temperatures will be reported. The mechanism of the pyridine hydrogenation on the reduced $(\mathrm{CoO})-\mathrm{MoO}_{3}-\mathrm{Al}_{2} \mathrm{O}_{3}$ catalyst is discussed on the basis of kinetic experiments on both the pyridine hydrogenation and the piperdine dehydrogenation and adsorption studies of pyridine and hydrogen.

\section{Experimental Section}

Procedures. The equipment used for the kinetic experiments has been described elsewhere. ${ }^{4}$ More detailed information is given in ref 5 for the pyridine hydrogenation and in ref 7 for the piperidine dehydrogenation. For the piperidine conversion at higher temperatures a reactor was used with an internal diameter of $4 \mathrm{~mm}$. Measurements with a thermocouple showed that the temperature drop over the catalyst bed was always within $2^{\circ} \mathrm{C}$. The height of the catalyst bed was about $2.5 \mathrm{~cm}$. Separate experiments showed that the influence of the metal wall of the reactor and of the internal and external diffusion on the conversion could be neglected. The stability
TABLE I: Conversion of Piperidine as a Function of Hydrogen Pressure ${ }^{a}$

\begin{tabular}{cccccr}
\hline$P_{\mathrm{H}_{2},}$, & \multicolumn{5}{c}{ Product composition, ${ }^{b} \mathrm{~mol} \%\left(P_{\mathrm{i}} / P_{\text {pipo }}\right)$} \\
\cline { 2 - 6 } $10^{5} \mathrm{~N} \mathrm{~m}^{-2}$ & $\mathrm{C}_{5}$ & pip & py & NPP & Loss \\
\hline 40 & 3.7 & 59.6 & 6.5 & 5.8 & 18.6 \\
50 & 4.6 & 61.1 & 4.4 & 7.5 & 14.9 \\
60 & 6.1 & 63.5 & 3.9 & 9.3 & 7.9 \\
70 & 6.4 & 65.6 & 2.7 & 9.9 & 5.5 \\
80 & 7.2 & 64.4 & 2.5 & 11.2 & 3.5 \\
90 & 7.6 & 65.2 & 2.2 & 11.8 & 1.4
\end{tabular}

${ }^{a} \mathrm{~T}=375^{\circ} \mathrm{C} ; P_{\text {pip }_{0}}=0.33 \times 10^{5} \mathrm{~N} \mathrm{~m}^{-2} ; 0.27 \mathrm{~g}$ of $\mathrm{CoO}-\mathrm{MoO}_{3-}$ $\mathrm{Al}_{2} \mathrm{O}_{3} ; t=0.14 \times 10^{7} \mathrm{~kg} \mathrm{~N} \mathrm{~s} \mathrm{~m}^{-2} \mathrm{~mol}^{-1}$. ${ }^{b}$ Products observed are pentane and pentene $\left(\mathrm{C}_{5}\right)$, ammonia (not well analyzed), pentylamine (very small amount), piperidine (pip), pyridine (py), and $n$-pentylpiperidine (NPP). The percentage loss is based on the balance of pentyl groups.

of the catalyst was good enough to ignore the decline in activity.

The reaction time is defined as $t=m P \phi_{\mathrm{t}}{ }^{-1}$ in which $m$ is the mass of the catalyst $(\mathrm{kg}), P$ is the total pressure $\left(\mathrm{N} \mathrm{m}^{-2}\right)$, and $\phi_{\mathrm{t}}$ is total moles fed to the reactor $\left(\mathrm{mol} \mathrm{s}^{-1}\right)$.

The product distributions have been determined by gas chromatographic analyses ${ }^{9}$ of samples taken from the gas stream or samples obtained after total condensation of the reaction products with the aid of liquid nitrogen.

Materials. The catalyst was $4 \% \mathrm{CoO}-12 \% \mathrm{MoO}_{3}-\gamma \mathrm{Al}_{2} \mathrm{O}_{3}$ (Ketjenfine, $235 \mathrm{~m}^{2} \mathrm{~g}^{-1}$ ) with particle diameter of $0.21-0.30$ $\mathrm{mm}$. Before use, the catalyst was reduced with hydrogen at $450^{\circ} \mathrm{C}$ for at least $16 \mathrm{~h}$.

Piperidine was distilled under a nitrogen atmosphere on molecular sieves and brought into the saturator immediately after distillation. The pyridine content of the piperidine was found to be very low.

\section{Results}

The conversion of piperidine has been studied at 350 and $375^{\circ} \mathrm{C}$ as a function of reaction time and hydrogen pressure. The influence of the hydrogen pressure on the piperidine conversion and the product distribution is shown in Table $\mathrm{I}$. The decreasing amount of pyridine at higher hydrogen pressures points to a negative order with respect to hydrogen. Determination of the order with respect to piperidine for this reaction was not possible because in our measurements the reaction time has not been varied sufficiently. However, from a discussion of adsorption constants of the relevant bases it can be concluded that this order is unity. ${ }^{5}$

At longer reaction times the pyridine-piperidine equilibrium was established. At $375^{\circ} \mathrm{C}$ we observed a constant ratio of about 7 between the pyridine and the piperidine partial pressures at $t>0.3 \times 10^{7} \mathrm{~kg} \mathrm{~N} \mathrm{~s} \mathrm{~m}^{-2} \mathrm{~mol}^{-1}\left(P_{\mathrm{H}_{2}}=60 \times 10^{5}\right.$ $\left.\mathrm{N} \mathrm{m}^{-2}, P_{\text {pip }}=0.33 \times 10^{5} \mathrm{~N} \mathrm{~m}^{-2}\right)$. Calculation of the equilibrium constant $K=P_{\mathrm{pip}} P_{\mathrm{py}}{ }^{-1} P_{\mathrm{H}_{2}}{ }^{-3}$ from these values showed a somewhat higher value $\left(3.2 \times 10^{-20}\right)$ than the one calculated from the data of Goudriaan ${ }^{6}\left(1.6 \times 10^{-20} \mathrm{~N}^{-3} \mathrm{~m}^{6}\right)$. This may point to the establishment of a pseudoequilibrium in our experiment. 6

\section{Discussion}

Kinetics of Piperidine Dehydrogenation. As discussed in the Introduction the kinetics of pyridine hydrogenation can be described by eq 2 in which $a=1.5$. The activation energy was found 6 to be $66 \mathrm{~kJ} \mathrm{~mol}^{-1}$.

In order to formulate the kinetics of the piperidine dehy- 
drogenation one has to take into account the facts that several reactions occur in the whole process and that the selectivity of the pyridine formation is rather low. From the results presented in Table I, the order with respect to hydrogen for the dehydrogenation of piperidine can be calculated by using the following reaction scheme:

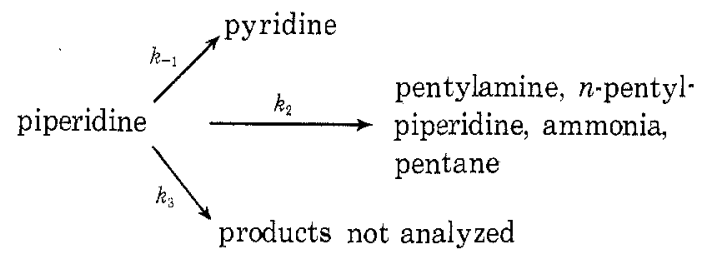

Here the complex cracking and hydrocracking reactions ${ }^{7}$ have been aggregated in reaction 2 . Reaction 3 is assumed to be a parallel reaction.

On the bases of the kinetics found for piperidine cracking and because the adsorption coefficients of the nitrogen bases are nearly equal, ${ }^{5}$ we formulate the rate equation of piperidine conversion:

$$
\begin{aligned}
& \frac{-\mathrm{d} P_{\text {pip }}}{\mathrm{d} t}=k_{-1} \frac{P_{\text {pip }}}{P_{\text {pip } 0}} P_{\mathrm{H}_{2}}{ }^{x} \\
& +k_{2} \frac{P_{\text {pip }}}{P_{\text {pip }_{0}}} P_{\mathrm{H}_{2}}{ }^{y}+k_{3} \frac{P_{\text {pip }}}{P_{\text {pip }_{0}}} P_{\mathrm{H}_{2}}{ }^{z}
\end{aligned}
$$

Integration of this yields

$$
\begin{aligned}
\frac{P_{\text {pipo }}}{t} \ln \frac{P_{\text {pipo }}}{P_{\text {pip }}}=k_{-1} P_{\mathrm{H}_{2}}{ }^{x}+k_{2} P_{\mathrm{H}_{2}}{ }^{y} & +k_{3} P_{\mathrm{H}_{2}}{ }^{2} \\
& =k_{-1} *+k_{2} *+k_{3} *
\end{aligned}
$$

From the piperidine conversion and eq 5 , the sum of the rate constants can be calculated; the ratios of the amounts of pyridine to cracking products $\left(2 P_{\mathrm{NPP}}+P_{\mathrm{C}_{5}}\right)$, and to the unanalyzed products formed give the individual rate constants $k_{i}^{*}$.

The data obtained for $k_{-1} P_{\mathrm{H}_{2}}{ }^{x}\left(=k_{-1}{ }^{*}\right)$ have been plotted in Figure 2 as a function of hydrogen pressures. An order of $1.44 \pm 0.26$ (90\% confidence region) with respect to hydrogen is found. Similar plots for $k_{2}{ }^{*}$ and $k_{3}{ }^{*}$ show an order of 0.8 with respect to hydrogen for the (hydro)cracking of piperidine, which is in agreement with previous results, ${ }^{7}$ and a rather high negative order with respect to hydrogen for the formation of heavy products not analyzed.

Two points may have an effect on the interpretation of the kinetics. They are the following:

(a) The establishment of the pyridine-piperidine equilibrium. The piperidine conversion into pyridine is found to be about $25 \%$ from equilibrium if the equilibrium constant is calculated from the data reported by Goudriaan. ${ }^{6}$ Correction of the results for the reverse reaction (pyridine $\rightarrow$ piperidine) will increase the order with respect to hydrogen for the piperidine dehydrogenation.

(b) Another reaction involving the formation of heavy products. The curved line for $k_{3} *$ in Figure 2 points to another reaction scheme, for instance, a consecutive reaction instead of a parallel reaction for the formation of products not analyzed. The negative order in hydrogen for $k_{3}{ }^{*}$ as well as the results of the piperidine conversion at low hydrogen pressure ${ }^{7}$ indicate the formation of heavy products from partly dehydrogenated piperidine. Incorporation of this possibility in the reaction scheme will result in a lower order in hydrogen for the piperidine dehydrogenation.

In conclusion, therefore, we may state that the order with

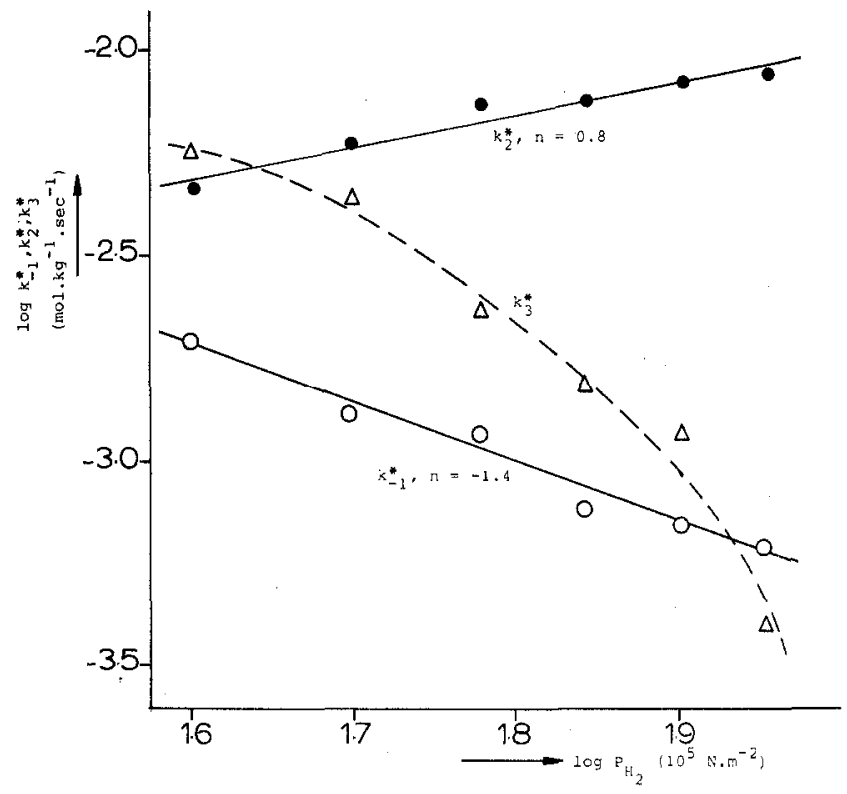

Figure 2. The three pseudo rate constants of the piperidine conversion reactions as a function of the hydrogen pressure (calculated from Table I): (O) $k_{-1}{ }^{*} ;(0) k_{2}^{*} ;(\Delta) k_{3}^{*}$.

respect to hydrogen for the piperidine dehydrogenation will lie between -1 and -2 . The rate equation for this reaction can be formulated as

$$
r_{\text {dehydrogenation }}=k_{-1} \frac{P_{\text {pip }}}{P_{\text {pip }_{0}}} P_{\mathrm{H}_{2}}{ }^{(-1 \grave{a} 2)}
$$

The Stoichiometric Number. According to Manes, Hofer, and Weller ${ }^{10}$ and Horiuti ${ }^{11}$ the following relation applies:

$$
k_{1} / k_{-1}=K^{1 / \gamma}
$$

where $K$ is the equilibrium constant $\left(=P_{\text {pipeq }}\right.$. $P_{\text {pyr }_{\mathrm{eq}}}{ }^{-1} P_{\mathrm{H}_{2 \mathrm{eq}}}{ }^{-3}$ ), and $\gamma$, the stoichiometric number of the rate-determining step of the reaction; i.e., the number of times the rate determining step of the reaction occurs, compared with the overall reaction. Values of $\gamma$ can be derived from eq 7 by means of: (a) the kinetic expression of the forward and the backward reactions; ${ }^{12}$ (b) the enthalpy of the reaction in comparison with the difference in energy of activation of the forward and the backward reactions; (c) the substitution of the values of $k_{1}, k_{-1}$, and $K$.

(a) At the equilibrium, the rate of dehydrogenation is equal to that of hydrogenation. Assuming the rate equations found also apply in the neighborhood of equilibrium, and combining eq 2 and 6 with $a=1.5$ and $P_{\mathrm{N}_{0}}=P_{\text {pip }}$, we obtain:

$$
k_{-1} \frac{P_{\text {pipea }}}{\mathrm{P}_{\mathrm{N}_{0}}} P_{\mathrm{H}_{2}}{ }^{-(1 \grave{a} 2)}=k_{1} \frac{P_{\text {pyr }_{\mathrm{eq}}}}{P_{\mathrm{N}_{0}}} P_{\mathrm{H}_{2}}{ }^{1.5}
$$

Combination of this result with eq 7 gives:

$$
\frac{P_{\text {pipeq }} P_{\mathrm{H}_{2}}-(1 \grave{a} 2) P_{\mathrm{N}_{0}}}{P_{\mathrm{pyr}_{\mathrm{eq}}} P_{\mathrm{H}_{2}}{ }^{1.5} P_{\mathrm{N}_{0}}}=\left(\frac{P_{\mathrm{pipeq}_{\mathrm{eq}}}}{P_{\mathrm{pyr}_{\mathrm{eq}}} P_{\mathrm{H}_{2}}{ }^{3}}\right)^{1 / \gamma}
$$

From eq 9 we conclude that $\gamma$ must have the value of unity. The kinetic equation of piperidine dehydrogenation, therefore, takes the form

$$
r_{\text {dehydrogenation }}=k_{-1} \frac{P_{\text {pip }}}{P_{\mathrm{N}_{0}}} P_{\mathrm{H}_{2}}^{-1.5}
$$

(b) Substitution of the exponential temperature functions of $k_{1}, k_{-1}$, and $K$ in eq 7 provides 


$$
E_{1}-E_{-1}=\Delta H^{\circ} / \gamma
$$

$E_{1}$ was found to be $66 \mathrm{~kJ} \mathrm{~mol}^{-1}$. Previously ${ }^{7}$ it was reported that $E_{-1}$ exceeds the value of $160 \mathrm{~kJ} \mathrm{~mol}^{-1}$. From a few measurements of the piperidine conversion as a function of temperature, the value of $E_{-1}$ was estimated to be $230 \mathrm{~kJ} \mathrm{~mol}^{-1}$. $\Delta H^{\circ}$ has a reported ${ }^{6}$ value of $-160 \mathrm{~kJ} \mathrm{~mol}^{-1}$. Substitution of these values in eq 11 also shows that $\gamma$ has a value of unity.

Because the values of $E$ and $E_{-1}$ are practically not influenced by the form of the kinetic expression for the relevant reactions, this method may be regarded not to depend on that described in section a.

(c) From the values of $k_{1}^{5}$ and $k_{-1}$, we calculated an equilibrium constant with a value of $6 \times 10^{-20} \mathrm{~N}^{-3} \mathrm{~m}^{6}$, assuming $\gamma=1$ in eq 7. This is quite in agreement with the value of $2 \times$ $10^{-20} \mathrm{~N}^{-3} \mathrm{~m}^{6}$ calculated from the data given by Goudriaan. ${ }^{6}$ This also supports that $\gamma=1$.

For two reasons this result must be regarded as practically independent of the others. The calculated values of $k_{1}$ and $k_{-1}$ remain in about the same order of magnitude when using rate equations different from (2) with $a=1.5$ and (10), respectively. Moreover, the value of $K$ differs largely from unity, so that from eq $7 \gamma$ can be calculated accurately. From these results it is obvious that the stoichiometric number of the rate-determining step of the pyridine hydrogenation into piperidine is unity.

Mechanism of Pyridine Hydrogenation. The following elementary steps may occur in pyridine hydrogenation:

$$
\begin{aligned}
& \text { pyridine (py) } \leftrightharpoons \text { pyads }_{\text {ads }} \\
& \text { hydrogen }\left(\mathrm{H}_{2}\right) \leftrightharpoons \mathrm{H}_{2_{\text {ads }}} \\
& \mathrm{H}_{2_{\mathrm{ads}}} \leftrightharpoons \mathrm{H}_{\mathrm{ads}}+\mathrm{H}_{\mathrm{ads}} \\
& \text { py } \mathrm{H}_{x_{\mathrm{ads}}}+\mathrm{H}_{2} \leftrightharpoons \text { py } \mathrm{H}_{(x+2)_{\mathrm{ads}}} \quad(0 \leqslant x \leqslant 4) \\
& \text { py } \mathrm{H}_{y_{\text {ads }}}+\mathrm{H}_{2_{\text {ads }}} \leftrightharpoons \text { py } \mathrm{H}_{(y+2)_{\text {ads }}} \quad(0 \leqslant y \leqslant 4) \\
& \text { py } \mathrm{H}_{z_{\text {ads }}}+\mathrm{H}_{\mathrm{ads}} \leftrightharpoons \text { py }_{(z+1)_{\text {ads }}} \quad(0 \leqslant z \leqslant 5) \\
& \text { pip }_{\text {ads }} \leftrightharpoons \text { piperidine }
\end{aligned}
$$

The stoichiometric number of unity means that the ratedetermining step occurs once with respect to the overall reaction. For the reaction steps $b$ and $c$ the value of $\gamma$ amounts to 3 . Hence, these steps cannot be rate determining under our reaction conditions.

Reaction steps a and $\mathrm{g}$ are not rate determining either. Deriving rate equations based on these suppositions and assuming a low coverage of the surface with hydrogen we get the rate equations $r_{\text {hydr }}=k P_{\mathrm{py}} P_{\mathrm{N}_{0}}{ }^{-1}$ and $r_{\mathrm{hydr}}=k P_{\mathrm{py}} P_{\mathrm{N}_{0}}{ }^{-1} P_{\mathrm{H}_{2}}{ }^{3}$, respectively. These are, however, in contradiction with the experimental results. Steps $d, e$, and $f$ of the reaction scheme given above remain as possible rate-determining steps. The order 1.5 with respect to hydrogen for the pyridine hydrogenation ${ }^{5}$ indicates one of the following steps to be rate determining:

$$
\text { py } \mathrm{H}_{\mathrm{ads}}+\mathrm{H}_{2} \rightarrow \text { py } \mathrm{H}_{3_{\mathrm{ads}}}
$$

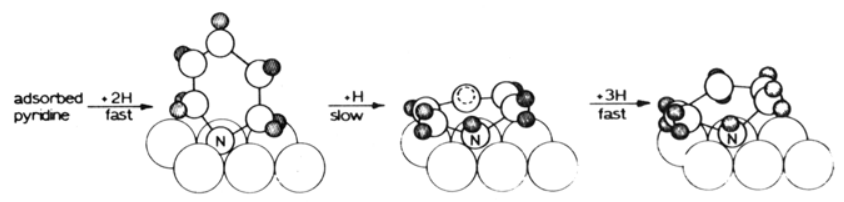

Figure 3. Scheme of the mechanism of pyridine hydrogenation.

$$
\begin{aligned}
& \text { py } \mathrm{H}_{\text {ads }}+\mathrm{H}_{2_{\text {ads }}} \rightarrow \text { py } \mathrm{H}_{3_{\text {ads }}} \\
& \text { py } \mathrm{H}_{2_{\text {ads }}}+\mathrm{H}_{\text {ads }} \rightarrow \text { py } \mathrm{H}_{3_{\text {ads }}}
\end{aligned}
$$

This result, showing that after the rather slow formation of trihydropyridine a further hydrogenation taking place fast, may be surprising. However, it is understandable if the state of adsorption of the pyridine molecule is considered. In our laboratory Fransen showed by means of infrared spectroscopic measurements of adsorbed pyridine on a reduced molybdenum oxide $-\mathrm{Al}_{2} \mathrm{O}_{3}$ catalyst that a fast exchange particularly between the surface OD groups and the ortho $\mathrm{H}$ of pyridine occurs. ${ }^{13}$ This points to a more or less perpendicular position of the pyridine molecule on the catalyst surface. This fact suggests that two hydrogen atoms may be added rapidly to the adsorbed pyridine, whereafter the slow uptake of the third hydrogen atom takes place and as a consequence the hybridization of the nitrogen atom is changed. The partly hydrogenated molecule may now move the unhydrogenated bonds to the surface, which in its turn may be rapidly hydrogenated. This supports the conclusion that reaction $\mathrm{j}$ is rate determining. This process is depicted in Figure 3. In this figure the hydrogen atoms are supposed to originate from the hydroxyl groups of molybdenum. The observation of the existence of separate adsorption sites for hydrogen and pyridine supports this mechanism.

Acknowledgment. We express our gratitude to Mr. T. Fransen for his valuable discussions.

\section{References and Notes}

(1) R. A. Flinn, O. A. Larson, and H. Beuther, Hydrocarbon Process Petrol. Refiner, 42, 129 (1963).

(2) J. Doelman and J. C. Vlugter, Proceedings of the World Petroleum Congress, 6th, Frankfurt, Germany, 1963, Section 3, paper 12-PD 6.

(3) H. G. Mcllvried, Ind. Eng. Chem., Proc. Des. Devel., 10, 125 (1971).

(4) J. Sonnemans, F. Goudriaan, and P. Mars, Proc. Int. Congr. Catal., 5th, 1085 (1972).

(5) J. Sonnemans, G. H. van den Berg, and P. Mars, J. Catal., 31, 220

(6) F. Goudriaan, Thesis, Twente University of Technol., Enschede, The Netherlands, 1974 (in English).

(7) J. Sonnemans, W. J. Neijens, and P. Mars, J. Catal., 34, 215 (1974)

(8) T. Fransen, unpublished results.

(9) T. Beugeling, M. Boduszyński, F. Goudriaan, and J. Sonnemans, J. Anal. Lett., 4, 727 (1971).

(10) M. Manes, L. J. E. Hofer, and S. Weller, J. Chem. Phys., 18, 1355 (1950).

(11) J. Horiuti, Adv. Catal., 9, 339 (1957)

(12) J. Happel, H. Blanck, and T. D. Hamill, Ind. Eng. Chem., Fundam., 5, 289 (1966).

(13) T. Fransen, O. van der Meer, and P. Mars, J. Phys. Chem., preceeding paper in this issue. 